\title{
Evaluation of Programs: Reading Carol H. Weiss
}

\author{
Vuyisile Msila ${ }^{1, *}$, Angeline Setlhako² \\ ${ }^{1}$ College of Education, Department of Education Leadership and Management, University of South Africa, UNISA, 0003, \\ Pretoria, South Africa \\ ${ }^{2}$ College of Education, Department of Curriculum Studies, University of South Africa, UNISA, 0003, Pretoria, South Africa \\ *Corresponding Author: msilavt@unisa.ac.za
}

Copyright (C 2013 Horizon Research Publishing All rights reserved.

\begin{abstract}
Carol Weiss did much to enhance the role of evaluation in her writings. Her work shows evaluators what affects their roles as they evaluate programs. Furthermore, her theory of change spells out the complexities involved in program evaluation. There are various processes involved in iti. the evaluation of programs. The paper looks at some of the aspects that inform this process. Effective evaluation of programs can lead to improvement of programs and good delivery of projects in future. It is Weiss who stated that evaluation should have an influence on policy and practice. Amongst other themes explored here are the politics of evaluation as well as the crucial role of the evaluator within the complexity of evaluation of programs.
\end{abstract}

Keywords Theory of Change, Policy Improvement, Politics, Complexity

\section{Introduction}

This article explores aspects of Carol Weiss's theory of change. Hanberger [1] cites several authors including Weiss who state that monitoring and evaluation are crucial in today's society; moreover, these authors support democratic governance and promote accountability as well as program improvement. Weiss [2] defines the purpose of evaluation as a process "to measure the effects of a program against the goals it set out to accomplish as a means of contributing to subsequent decision making about the program and improving future programming". Her interest in evaluation was always to examine the goals that the program itself promulgated. Evaluation needs to influence decision making as it ensures that the evaluation will be able to improve future programs. Weiss' theory [3] has also been influenced by the political situation as all programs tend to be influenced by a certain political atmosphere. This then means that the political context affects the work of evaluators; evaluators are pressured by political influences.

In fact, Weiss and Alkin [4] contend that there are three principal ways in which politics encroach on program education:

i. Programs are created and maintained by political forces:

ii. (Higher echelons of government, which make decisions about programs are embedded in politics; and

iii. The very act of evaluation has political connotations. Weiss is aware of the challenges that the evaluation process constantly encounters. Sometimes it might not be easy for an evaluator to have appropriate tools and techniques to understand fully what is going on (Weiss 1998).

Furthermore, Weiss [5] argues: Theory-based evaluation is one approach that has a great deal of promise. But trying to use theory-based evaluation is difficult when programs do not have any explicit- or even implicit-theories, when programs are amorphous, or when they shift significantly over time. Evaluators cannot rely solely on their expertise in research methodology any longer. They have to understand the program field.The above shows the need to plan for evaluation thoroughly.

Weiss stresses the need for evaluators to understand a program and how it works well. This author speaks of what she calls evaluation appreciation. She argues that for practitioners to conduct effective evaluation they need to understand what evaluation is all about as well as what it takes to conduct a good study. Furthermore, evaluators need to know what to do with evaluation results. Hanberger [1] highlights that there is interplay between evaluation and governance and that all evaluation systems are crucial in democratic governance.

Whilst this paper focuses on the work of Carol Weiss one should be aware of the broad themes agreed upon by evaluators. Effective evaluations lead to the improvement of programs and good delivery of projects in future. Of crucial importance is that evaluation should have an influence on policy and practice [6]. The latter promulgation has influenced a number of evaluation experts. However, [6] argue that there is general consensus and that evaluation is mainly used in three ways; firstly, it is used to give direction to policy and practice; secondly, it is used to justify pre-existing preferences and actions and finally, to provide new generalizations, ideas and concepts. All those involved in social policymaking need effective evaluation strategies 
based on sound theory. Programs are usually very complex and frequently need effective program theory for evaluation. However, there are considerable challenges to program theory and not all evaluators are convinced it is useful [7]. Furthermore, [7] argues that sometimes referred to as program logic or theory of change it points to a variety of ways of developing a causal modal linking program inputs to a chain of observed outcomes and then using this model to guide evaluation. Various simple logic models explicate the theory of change espoused by experts such as Rogers, Funnell and Weiss. Rogers, Huebner and Hacsi [8] consider program theory of evaluation to have two essential components, one perceptual and the other empirical. It is crucial to utilize theories well when conducting evaluations. Rogers et al. [8] assert:

In some evaluations, the program theory has been developed largely by the evaluator, based on a review of research literature on similar programs or relevant causal mechanisms, through discussions with key informants through a review of program documentation, or through observation of the program itself (Lipsey and Pollard, 1989). In other evaluation, the program theory has been developed primarily by those associated with the program, often through a group process.

When employing any permission to evaluate the practitioners are interested in exploring the ultimate outcomes. The outcomes will eventually impact on policy. This paper explores Weiss understand the Theory of Change

\section{The Theory of Change}

As seen in the discussions above, Weiss is linked to this concept which she has used widely in her work as an evaluator [9]. She argues that many programs are so difficult to evaluate because they are based on poorly articulated assumptions. Weiss emphasizes the need to look at the mini-steps if a long term outcome is to be attained. She also stresses policy makers to be specific about the theories of change that guide their work arguing that this clarity would help improve policies and enhance their ability to claim credit for outcomes that were predicted in their theory [9]. Leeuw [10] lists steps that elicit the theory of change underlying a planned program. These enforce the evaluator to work with a wide range of stakeholders. These are the steps:

STEP 1: The focus is on long term vision of a program and likely to relate to a time scale that lies beyond its timeframe. STEP 2: Having agreed the ultimate aim of the program stakeholders are encouraged to consider the necessary outcomes that will be necessary by the end of the program. STEP 3 \&STEP 4: Stakeholders are asked to articulate the types of outputs and short-term outcomes that will help them achieve the specified targets. The theory of change was lauded by Weiss as practical and effective to communities engaged in transformation efforts. The Organizational Research Services [11] succinctly summarises this theory of change:

Every community needs a roadmap for change. Instead of bridges, avenues and freeways, this map would illustrate destinations of progress and the routes to travel on the way to achieving progress. The map would also provide commentary about assumptions, such as the final destination, the context for the map, the processes to engage in during the journey and the belief system that underlies the importance of travelling in a particular way. This type of map is called a "theory of change".

This theory is a clear road map for change, sometimes referred to as the logic model it guides those engaged in the change process. The theory of change ensures that those engaged on a journey to change process do not lose their direction. It is unthinkable to contemplate the success of any transformation guidelines without clear guidelines: the theory of change. One of the useful techniques of the theory of change is to employ an outcome map which is a visual diagram that spells out relationships between initiative strategies and intended results. The theory of change usually yields two products: An outcome map and a list of assumptions about change [11]. Therefore, Weiss's theory of change is an approach that shows why an initiative works or does not [12]. Moreover, the theory of change seeks to improve how programs are implemented. Weiss perceives this theory and its role in evaluation research. Mapping theories of change, the politics of evaluation, theory of change for planning evaluation, managing for outcomes and logic modelling are some of the topics which are relevant to Weiss as she explicates the theory of change.

\section{The Complexity in the Theory of Change}

Stame [13] points out that the theory-based evaluations have assisted in opening the "black box" of programs. This author defines the black box as the space between the actual input and the expected output of the program. In a section below, the discussion will briefly focus on how Weiss perceives the role of politics in evaluation. Weiss points out that programs are confused and frequently program theory is affected by politics. To illustrate this complexity, Stame [13] writes:

For Weiss programs do have theories although as confused as a level of muddling through permits. The black box is full of many theories. She calls them 'theories of change' (Weiss, 1995): they take the form of assumptions, tacit understandings, etc.: often more than one for the same program. In a remarkable effort (Weiss, 1995:74), she lists seven assumptions, and many more sub-assumptions, that could underlie a program on the provision of services in comprehensive community initiatives.

Just like her contemporaries such as Chen and Patton, Weiss underscored the challenges of evaluating programs. A publication of the treasury Board of Canada Secretariat [14] points out that over the past two decades the theory-based 
approaches have moved into the mainstream of thinking and practice about how interventions are designed and evaluated. These can help evaluators address a variety of challenges, such as coming to terms with the inherent complexity of certain types of interventions.

\section{The Politics of Evaluation}

Weiss refers to evaluation research as a rational enterprise. However, she highlights the political constraints and resistances that exist. Weiss [15] argues:

But evaluation is a rational enterprise that takes place in a political context. Political considerations intrude in three major ways, and the evaluator who fails to recognize their presence is in for a series of shocks and frustrations: First, the policies and programs with which evaluation deals are the creatures of political decisions. They were proposed, defined, debated, enacted, and funded through political processes and in implementation they remain subject to pressures - both supportive and hostile - that arise out of the play of politics.

Weiss further adds that evaluation's reports enter the political arena and assume a political stance. Even programs that are evaluated are political creatures. "The programs with which the evaluator deals are not neutral, antiseptic, laboratory-type entities. They emerged from the rough and tumble of political support, opposition and bargaining" [15]. However, before we explore her theory, it is fitting to briefly look at what other evaluation experts say about the influence of politics in research. Cohen, Manion and Harrison [16] cite MacDonald who states that evaluation is inherently political. Furthermore, this author has characterized evaluation as having threefold qualities; autocratic, bureaucratic as well as democratic. "However, the truth of the matter is far more blurred than these distinctions suggest. Two principal causes of this blurring lie in the funding and the politics of both evaluation and research" [16]. Research is always affected by what is happening in society. Weiss takes evaluation as step further as she proclaims that evaluations should help in decision making. Rowe and Taylor [17] concur as they point out:

Evaluation makes little sense unless it is understood as part of a learning process. Learning distinguishes it from audit, performance management and reporting. Indeed, for some, evaluations should be explicitly framed to ensure their use by policymakers and other stakeholders, including practitioners (Patton, 1997). Without wishing to engage in the methodological implications of such an approach, it is common to assume that evaluations of public services will, in some way, contribute to a body of knowledge and understanding...

Weiss looks at how the evaluator has to face the task of sifting the real from the unreal. Furthermore, she argues that the evaluators have to direct their research towards genuine goals [15]. As pointed out above, the politics can undermine evaluation. Furthermore, Weiss [5] asserts:

While the evaluation study is in progress, political pressured can alter or undermine it. Let us look at one final example of how organizational politics can affect the shape of evaluation research. Programs do not always keep to their original course; over time, often a short span of time, they can shift in activities and in overall strategies even in the objectives they seek to attain.

Unfortunately, frequently programs are clouted by politics and this makes the work of evaluators very difficult. In the above extract, Weiss explains that the political pressures can change the course of a program hence one will be certain that in turn evaluation will be affected. Costan [18] argues that there are scholars who like Weiss explain the political aspect in research. Costan points out that on the one hand evaluation has a rational analytical school whose scholars state that the goals of evaluation are to seek "the truth". While on the other, the responsive school points out that there is no unique reality i.e. the scope of evaluation as the quest for truth. "In the responsive school tradition, the evaluation forms part of a continuous process driven by political and other interests that may be leading at bets to some agreement on images of realities" [18]. This necessitates the role of the evaluator to transform and be that of a negotiation process. Here the evaluator's role is to ensure that consensus is reached; this is what political constraints can do to evaluations. In the section below the focus is on some of the "hazards" Weiss highlights as responsible in making evaluation increasingly political [2].

\section{Relationships with Funding Bodies}

Weiss points out an important supposition when she states that evaluation money today is given out with restrictions. Usually the government's request for proposals specify what needs to be accomplished by the research, it also specifies details of objectives, indicators, timing, analysis and reporting. In short, the government agencies want to closely monitor the processes of evaluation during the course of the study. Some of these agencies would want biweekly conferences or monthly reports to ensure that all is still on track. "Government agencies may seek only to enforce standards of relevance and research quality, but they almost inevitably become suspect of political pressure, pressure to vindicate the program and justify its budget" [2].

\section{Relationships with Program Personnel}

Few program staff like evaluators who want to measure the success or outcomes of a program they are running. Program drivers who "know" that their program is doing well, the evaluation is unnecessary and if shows few positive aspects it becomes a threat to the future of the program. These might offer reasons why data given to the evaluators may be limited. "Occasionally what program staff deems more 'relevant data' may be supplied. Even where this is not 
so, the general atmosphere of uncordiality can dim the evaluator's spirit and his study" [2].

\section{Drawing Recommendations}

Due to the political context of evaluation, the act of drawing implications from study data becomes chancier than ever. As pointed out above, Weiss refers to evaluation as a "black box" studies. The evaluator takes measurements on factors relating to program goals before measurement on factors relevant to program goals. The evaluator may then conclude that the program has succeeded in achieving its goals to the observed extent. When exercising the black box studies evaluators jump to recommendations without providing the necessary data.

\section{Null Results}

The greatest political problem in evaluation is when results turn out to be negative. There are a number of instances where the evaluator has to relay the results that an evaluated program does not show any success. Weiss argues though that null evaluation results should not lead to the discontinuation of programs but rather to their improvement. Evaluators can and should make use of null results. Weiss [15] argues:

For a time, it may be a reasonable response to call attention to possible variations that may increase success-higher levels of funding, more skilled management, better trained staff, better coordination with other services, more intensive treatment and so on. If these recommendations are ignored, if the political response is to persist with the same low cost, low-trouble program, there is not much more that the social scientist can learn by evaluating participant outcomes.

Weiss also adds that there needs to be a thorough re-examination of the primary problem. Moreover, she argues that, "it is important to improve the craft of evaluation so that we have greater confidence in its results." Weak measurement reliability, according to Weiss gives rise to the null effect.

\section{The Role of the Evaluator}

Luo [19] writes about the role of the evaluator and describes it as a fundamental issue for evaluation. Luo [19] differentiates between five perspectives on the envisaged roles of evaluators. Among these are Weiss's views on the role of the evaluator. Luo [19] points out: Weiss emphasizes the evaluator's special role in promoting the use of his/her evaluation results, especially in the policy-making process. She is frustrated about the fact that "evaluation results have generally not exerted significant influence on program decisions," and she argues that evaluation should start out with the use of evaluation to the natural processes of discrimination and application. Weiss claims that evaluation "should be continuing education for program manager, planners and policy makers".... She urges evaluators to look beyond the instrumental use of evaluation results and conduct "enlightenment" research that "provides evidence that can be used by men and women of judgment in their efforts to research solutions".

Luo [19] examines the strengths as well as weaknesses in Weiss's theory. He points out that Weiss differentiates between the role of the evaluator from the role of a researcher by addressing the complex political process explored above. Weiss also wants to see evaluators engaged in evaluation that can be used in policy-making in the form of "enlightenment" rather than instrumental use". Barbier [20] endorses this when he states that the evaluator is not merely a technician meeting the client's needs but is expected to use his or her own room for maneuver. And again as seen above politics threaten the evaluator's involvement and it can be very difficult for them to avoid politics. As pointed out above, Weiss [15] argues that evaluations have to take political stances. Evaluators will have to live with this reality although Weiss points it out clearly that evaluation standard has to favor the public general interest at all times. Conley-Tyler [21] highlights that most evaluators emphasize the importance of gathering knowledge about the program being evaluated so as to ensure that the evaluation reflects the program and its context. These authors differentiate between internal and external evaluators. Internal evaluators tend to understand the population served the program under study as well as the staff. Furthermore, Conley-Tyler [21] asserts:

This means that internal evaluators have an advantage over external evaluators since they work in the environment in which the program operates and may have been personally involved in some part of the program planning Weiss 1972, p.38). As part of the organization, internal evaluators have first-hand knowledge of the organization's philosophy, policies, procedures, personnel and management.

However, despite this important role of the internal evaluator, external evaluators have a huge role to play. Weiss [2] stresses that when selecting evaluators, role-players should look both at skills and experience. Weiss points out that organizations are prone to select academic researchers with credentials as they ignore the valuable internal expertise. Yet many would prefer people with no stake in the program for the sake of objectivity. Internal evaluators are usually viewed with skepticism; not being objective or reliable - this is what [2] refers to as the "lingering suspicion". A number of authors have underscored the role of evaluation methods in determining the effectiveness of evaluation. Skoletset al. [22] postulates:

Some evaluation theorists suggested that traditionally an evaluators' choice of an evaluation method determined his/her evaluator role (Greene, 2000; Mark, 2002; Weiss, 1998). Weiss (1998) asserted that the traditional and still dominant role of conceptualization of evaluators is methods based and representative of a neutral, detached social 
scientist: "The traditional role of the inquiry...She put his trust in methodology" (p.90). Weiss also noted that role conceptualizations of evaluators were beginning to shift toward viewing the evaluator as more of a collaborator with program staff.

\section{Conclusion}

This paper examined the complexity of evaluation. In her theory Weiss illustrates it well that the theory of evaluation encompasses a number of aspects that evaluators need to understand. A wise evaluator will try and understand the various processes involved in evaluation process. Weiss also clearly supports programs of planned social change. She also adds that if real change is to happen evaluation should follow a well-drawn map. Finally, Weiss is also aware that the political pressures cannot be avoided during any evaluation process. In fact, she maintains that political processes have become part of evaluations of programs today.

\section{REFERENCES}

[1] A. Hanberger. Framework for exploring the interplay of governance and evaluation, Scandinavian Journal of Public Administration, Vol.16, No.3, 9-28.

[2] C.H. Weiss. The Politicization of Research, In C.H. Weiss (Ed). Evaluation action Programs: Readings in Social Action and Education, Prentice Hall, Boston, 1972a.

[3] C.H. Weiss. Evaluation Research: methods for assessing program effectiveness, Englewood Cliffs, 1972b.

[4] C.H.Weiss, M. Alkin, Rooting for evaluation: Evaluating roots. Sage, Thousand Oaks, 2004.।

[5] C.H. Weiss, Have we learned anything new about the use of evaluation? American Journal of Evaluation, Vol. 19, No. 1, 21-33.

[6] C.H. Weiss, E. Murphy-Graham, S. Birkeland, "An alternative route to policy influence: How evaluation affects D.A.R.E", American Journal of Evaluation, Vol. 26, No. 1, 12-30.

[7] P.J. Rogers, Using Program Theory to Evaluate Complicated and Complex aspects of Interventions. Evaluation, Vol. 14, No. 1, 29-48.
[8] P.J. Rogers, T.A. Huebner, T.A. Hacsi, Causal Models in Program Theory Evaluation. Directions for Evaluation, Vol. $87,47-55$.

[9] C.H. Weiss, The Haphazard Connection: Social Science and Public Policy. International Journal of Education Research, Vol. 23, No. 2, 137-150.

[10] Online Available: http://ec.europa.eu/regional_policy/inform ation. Leeuw, F.L, Online.

[11] Organizational Research Services, Theory of Change: A Practical Tool for action, Results and Learning, ORS, Washington, 2004.

[12] J.P. Connell, A.M. Klem, You can get there from here: Using theory of change approach to plan Urban Education Reform, Journal of Educational and Psychological Consulting, Vol.11, No. 1, 93-120.

[13] N. Stame, Theory-based Evaluation and types of Complexity. Evaluation, Vol. 10, No 1, 58-76.

[14] Board of Canada Secretariat, Theory-based approaches to Evaluations: Concepts and Practices. The Author, Ottawa.

[15] C.H. Weiss. Where Politics and Evaluation Research Meet, Evaluation Practice, Vol. 14, No. 1, 93-106.

[16] L. Cohen, L. Manion, K. Morrison, Research Methods in Education. Routledge, London, 2008.

[17] M. Rowe, M. Taylor, Community-led regeneration: Learning loops or reinvented wheels? In D. Taylor, S. Balloch. The Politics of Evaluation: Participation and Policy Implementation. Policy Press, Bristol, 2005.

[18] D.M. Costan. The Politics of Evaluation in Co-financed Projects: The Case of the Scottish Executive and the Evaluation of the Structural Funds. Romanian Journal of European Affairs, Vol. 9, No. 2, 33-45.

[19] H. Luo. The role for an evaluator: A fundamental issue for evaluation of education and social programs. International Education Studies, Vol. 3, No. 2, 42-50.

[20] J. Barbier. Inter-governmental Evaluation: balancing Stakeholders' Expectations with Enlightment Objectives? Evaluation, Vol. 5, No. 4, 373-386.

[21] M. Conley-Tyler. A Fundamental Choice: Internal or External Evaluation? Evaluation Journal of Australasia, Vol. 4, No. 1\&2, 3-11.

[22] G.J. Skolits, J.A. Morrow, E.M. Burr, Reconceptualizing Evaluator Roles. American Journal of Evaluation, Vol. 30, No. 3, 275-295. 